\title{
Exhaled nitric oxide in asthmatic children exposed to relevant allergens: effect of flunisolide
}

\author{
G.L. Piacentini*, A. Bodini*, S. Costella**, L. Vicentini*, P. Mazzi*, Y. Suzuki*, \\ D. Peroni*, A.L. Boner*
}

Exhaled nitric oxide in asthmatic children exposed to relevant allergens: effect of flunisolide. G.L. Piacentini, A. Bodini, S. Costella, L. Vicentini, P. Mazzi, Y. Suzuki, D. Peroni, A.L. Boner. (C) ERS Journals Ltd 2000.

ABSTRACT: Inhaled corticosteroids are capable of reducing the level of exhaled nitric oxide (expiratory nitric oxide fraction (FE,NO)) in asthmatic patients in a dosedependent fashion. The aim of this study was to evaluate whether or not treatment with an inhaled steroid can prevent changes in FE,NO after the exposure to relevant allergens, following avoidance, in asthmatic children allergic to house dust mite.

Thirty-two house dust mite-allergy asthmatic children were randomly allocated to treatment with inhaled flunisolide $(500 \mu \mathrm{g}$ b.i.d.) or placebo and evaluated before and 2 weeks after a period of natural exposure to mite antigens. Lung function and FE,NO were evaluated.

FE,NO was increased in the placebo-treated group after antigen exposure. Treatment with inhaled flunisolide prevented such increase in FE,NO $(p<0.001)$. No change was observed in lung function parameters.

Inhaled flunisolide is effective in preventing the increase in airway inflammation observed in allergic asthmatic children re-exposed to allergens. Eur Respir J 2000; 15: 730-734.

It is well recognized that asthma is an inflammatory disease and that indoor allergens, in particular house dust mite, represent a relevant factor in the aetiology of the disease [1]. It has been demonstrated that the development or worsening of asthma symptoms in children may be alleviated by allergen avoidance $[2,3]$ or by suppressing the bronchial response to allergen challenge [4-9].

In recent years, different markers have been proposed for the evaluation of level of airway inflammation [10]. Among these, the measurement of exhaled nitric oxide levels (expiratory nitric oxide fraction (FE,NO)) is considered a noninvasive means of assessing the degree of airway inflammation in asthmatics [11-13].

Recent studies have shown that inhaled corticosteroids are capable of decreasing the FE,NO in asthmatic patients in a dose-dependent fashion $[14,15]$.

In this study, whether treatment with an inhaled steroid can prevent changes in FE,NO after a brief period of exposure to relevant allergens was evaluated in a group of asthmatic children allergic to house dust mite.

\section{Material and methods}

\section{Subjects}

Thirty-two children (26 males and six females), ranging in age 6-15 yrs and with a history of bronchial asthma and a positive skin-prick test to house dust mite, were evaluated at the "Istituto Pio XII" long-stay hospital (Misurina, Belluno, Italy), situated at an altitude of $1,756 \mathrm{~m}$ in the Italian Alps. None of the patients had had respiratory infections for $\geq 2$ months before the beginning of the study and none of them were allergic to furry pets.
*Clinica Pediatrica, Universita' di Verona, Verona, Italy. **Istituto Pio XII, Misurina, Belluno, Italy.

Correspondence: A.L. Boner, Clinica Pediatrica, Policlinico Borgo Roma, 37134 Verona, Italy. Fax: 390458200993

Keywords: Airway inflammation allergen avoidance asthma corticosteroid nitric oxide

Received: April 271999 Accepted after revision January 202000

This study was supported, in part, by Valeas, Milan, Italy.
None of the children had received oral corticosteroids for $\geq 2$ months or inhaled corticosteroids for $\geq 1$ month before the study since they were staying in a house dust mite-free environment.

The study was approved by the Istituto Pio XII Ethics Committee and both children and their parents gave informed consent.

\section{Study design}

The study was performed between December 1997 and January 1998. The children admitted to the study had been living at the Istituto Pio XII, an environment free of house dust mite allergen because of its location at high altitude, for $\geq 3$ months at the time of admission $(t 0)$. The first set of evaluations ( $t 0)$ was performed immediately before the children left the Istituto Pio XII to spend the Christmas holidays at their family homes, at sea level, and before the first administration of flunisolide. The second set of evaluations $(t 1)$ were performed at the time of readmission to the Istituto Pio XII, after the children had been re-exposed to house dust mite allergens for 2 weeks. This study was performed out of the pollen season in order to avoid interference of outdoor allergens for those patients who were also sensitized to pollens.

The evaluations at $t 0$ and $t 1$ consisted of the measurement of pulmonary function and FE,NO. During the study period, symptoms were recorded daily. Patients were randomly divided into two parallel groups of 16 subjects each, receiving either flunisolide (Lunibron A; Valeas, Milan, Italy; $500 \mu \mathrm{g}$ b.i.d.) or placebo solution in a double-blind fashion. The treatments were started at the time that the children left the residential house and continued during the 
time they spent in their parents' houses. Treatments were administered via the same model of pneumatic nebulizer (Mefar, Bovezzo, Italy), which was provided to all the patients.

Inhaled $\beta_{2}$-agonists were allowed as needed. Neither cromons nor inhaled steroids, other then flunisolide administered in double-blind fashion according to the experimental design, were allowed for the duration of the study.

\section{Lung function and nitric oxide measurement}

Lung function was measured using a Vitalograph Compact spirometer (Vitalograph, Buckingham, UK). The forced expiratory volume in one second (FEV1) and forced mid-expiratory flow (FEF25-75) were considered in the analysis of results. The FE,NO was measured using a chemiluminescence analyser (Logan LR 2149; Logan, Rochester, UK) before performing spirometry $[14,15]$.

Briefly, the subjects were asked to perform a single slow exhalation starting from total lung capacity through a mouthpiece, against a resistance (mouth pressure $>5 \mathrm{~cm}$ $\mathrm{H}_{2} \mathrm{O}$ ) and with biofeedback used to maintain a steady flow of $5 \mathrm{~L} \cdot \mathrm{min}^{-1}$. This method allows the separation of the nasopharynx from the oropharynx by the soft palate, hence preventing the contamination of the FE,NO with nasal NO. This method has been shown to be successfully applicable in both adults and children. The FE,NO was measured at the plateau of the end-expiratory reading and expressed in parts per billion (ppb) according to guidelines [16]. The FE,NO considered in the data analysis were always measured at the plateau FE,NO, taking the plateau of the endexpiratory carbon dioxide reading as representative of an alveolar sample $[13,17]$.

\section{Measurement of mite allergen levels}

Parents were asked to collect dust from the mattresses of the subjects participating in the study in a standardized fashion, by vacuuming the mattress surface over an area of $\sim 2 \mathrm{~m}^{2}$ for $5 \mathrm{~min}$ [18] using a vacuum cleaner containing a new bag. Bags containing samples were stored in a sealed plastic bag at $4{ }^{\circ} \mathrm{C}$ until the dust was processed for measurement of mite group I allergen levels, which was performed using monoclonal antibodies in a two-site immunometric enzyme-linked immunosorbent assay (ELISA) $[19,20]$.

The results were expressed in micrograms of mite group I allergens per gram of dust [21].

\section{Statistical analysis}

The FE,NO and lung function (FEV1 and FEF25-75) evaluated at $t 0$ and a $t 1$ were statistically evaluated using multiple regression analysis [22] of the two regression lines for flunisolide and placebo ( $t 0$ versus $t 1$ ): the dependent (y) variable is the value measured at $t 1$ for each parameter and each patient, whereas the independent (x) variable is the value measured at $t 0$. Maximal protection is represented by a slope which is not significantly different from the line of identity, i.e. there were no significant changes in the investigated parameters between to and $t 1$. This was tested by evaluating the following null hypothesis: 1) The parallelism of the two regression lines (flunisolide: $y=a F 1+b F l x$; placebo: $y=a P 1+b P l x)$ to the theoretical line $(y=a+b x)$ with slope (b) equal to 1 and the intercept of the y-axis (a) equal to 0 (line of maximum protection to allergen exposure (LMPAE): $y=x$ ), where $\mathrm{aFl}$ and $\mathrm{bFl}$ are the $\mathrm{a}$ and $\mathrm{b}$ for flunisolide and $\mathrm{aPl}$ and $\mathrm{bPl}$ are the $a$ and $b$ for placebo, giving $b F l$ and $b P l=1$. 2) The coincidence of each regression line with the LMPAE (aFl or $\mathrm{aPl}=0$ ), if the parallelism hypothesis is verified. 3 ) The coincidence between the two regression lines $(\mathrm{aPl}=\mathrm{aFl})$, if $\mathrm{aFl}$ and $\mathrm{aPl} \neq 0$. The comparisons were carried out using a t-test utilizing the regression coefficients of the multiple regression model adopted.

Bronchial symptoms were analysed by comparing the sum of a score ranging 0-3 for daytime cough, night-time cough and wheezing using the Mann-Whitney U-test.

\section{Results}

Of the 32 children who were admitted (table 1), 28 completed the study. One child in the placebo group presented with an upper respiratory tract infection and three in the flunisolide-treated group were not compliant with the scheduled regimen, as verified by checking the personal diary card and evaluating the quantity of unused drug at the end of the study period. These subjects were excluded from the study and therefore the final analysis for the two groups included 15 placebo and 13 flunisolide subjects.

It was possible to obtain dust samples from 25 of the 28 children who completed the study. Four samples, one in the placebo and three in the flunisolide group, were not suitable for analysis because the quantity of dust collected was not sufficient to perform the allergen extraction. The mean level of mite allergen in samples collected in the residential house was $0.04 \mu \mathrm{g} \cdot \mathrm{g}$ dust $^{-1}$. The levels of house dust mite group I allergens (Der $p \mathrm{I}$ and Der fl) were $16.46 \mu \mathrm{g} \cdot \mathrm{g}$ dust $^{-}$in the placebo group and $12.84 \mu \mathrm{g} \cdot \mathrm{g} \mathrm{dust}^{-1}$ in the flunisolide-treated group (NS between treatments and $\mathrm{p}<$ 0.01 versus level in the residential house).

The individual and mean \pm SEM FE,NO, FEV1 and FEF2575 at $t 0$ and $t 1$ are shown in figures $1-3$.

The FE,NO were comparable in the two groups at $t 0$. The results of the multiple regression analysis carried out for FE,NO, FEV1 and FEF25-75 show that the placebo regression line is not coincident with the LMPAE placebo versus $\mathrm{LMPAE}, \mathrm{p}<0001)$ for $\mathrm{FE}, \mathrm{NO}$. In contrast, a significantly lower FE,NO was observed in the group treated
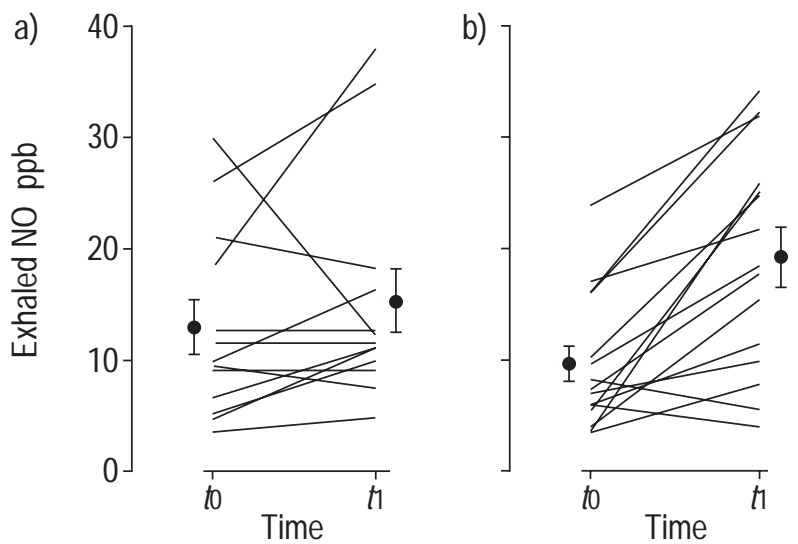

Fig. 1. - Expiratory nitric oxide fraction at the time of admission $(t 0)$ and 2 weeks later following re-exposure to house dust mite allergens in: a) the flunisolide group; and b) the placebo group ( $t 1)$. Data are presented as individual values and mean \pm SEM. ppb: parts per billion. 

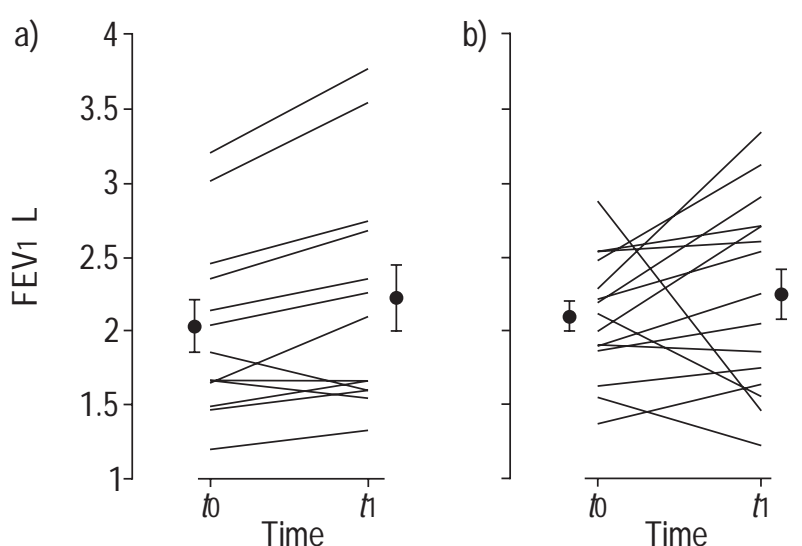

Fig. 2. - Forced expiratory volume in one second (FEV1) at the time of admission ( $t 0)$ and 2 weeks later following re-exposure to house dust mite allergens in: a) the flunisolide group; and b) the placebo group ( $t 1)$. Data are presented as individual values and mean \pm SEM.

with flunisolide, compared to placebo, after returning to the residential house (flunisolide versus placebo, $\mathrm{p}<0.05$ ), suggesting no significant changes in the flunisolide group, and, in addition, no significant difference was observed between the flunisolide regression line and the LMPAE line (flunisolide versus LMPAE, $\mathrm{p} \geq 0.05$ ).

When FEV1 and FEF25-75 values are considered, both the placebo and flunisolide regression lines are coincident with the LMPAE (placebo and flunisolide versus LMPAE, $\mathrm{p}>0.05$ ).

The mean daily symptom score was 0.72 for the flunisolide-treated group and 1.12 for the placebo treated group (NS).

\section{Discussion}

It has previously been demonstrated that inhaled corticosteroids are effective in preventing the increase in bronchial reactivity in allergic asthmatic children re-exposed to allergens for 3 months [9].

FE,NO has been demonstrated to be more promptly modified by exposure to or avoidance of relevant allergens in allergic asthmatic children $[23,24]$ than lung function.
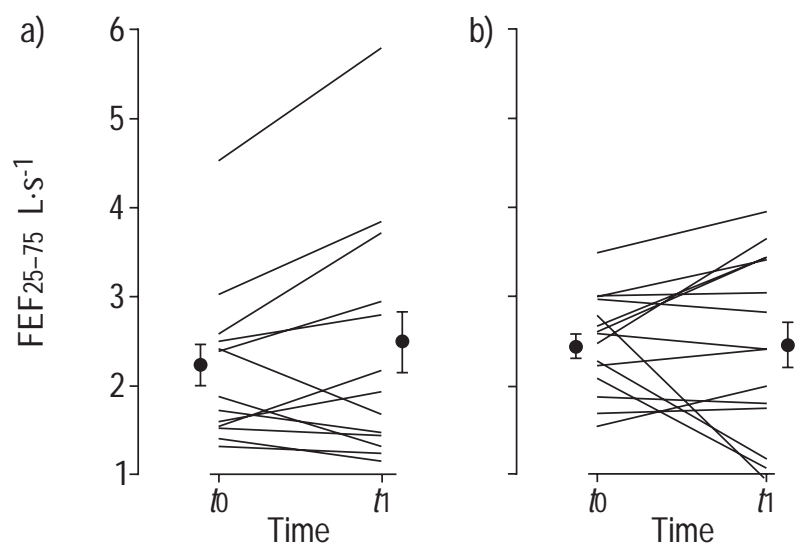

Fig. 3. - Forced mid-expiratory flow (FEF25-75\%) at the time of admission $(t 0)$ and 2 weeks later following re-exposure to house dust mite allergens in: a) the flunisolide group; and b) the placebo group $(t 1)$. Data are presented as individual values and mean \pm SEM.
Table 1. - Patient characteristics

\begin{tabular}{|c|c|c|c|c|c|c|}
\hline \multirow[b]{2}{*}{$\begin{array}{l}\text { Patient } \\
\text { No. }\end{array}$} & \multirow[b]{2}{*}{ Treatment } & \multirow[b]{2}{*}{ Sex } & \multirow[b]{2}{*}{$\begin{array}{l}\text { Age } \\
\text { yrs }\end{array}$} & \multirow[b]{2}{*}{$\begin{array}{c}\text { Height } \\
\mathrm{cm}\end{array}$} & \multicolumn{2}{|c|}{ to } \\
\hline & & & & & $\begin{array}{c}\text { FEV1 } \\
\text { L }\end{array}$ & $\begin{array}{c}\text { Rev } \\
\%\end{array}$ \\
\hline 1 & Flunisolide & M & 12 & 160 & 2.49 & 12 \\
\hline 2 & Flunisolide & M & 8 & 129 & 1.49 & 17 \\
\hline 3 & Flunisolide & M & 10 & 127 & 1.58 & 1 \\
\hline 4 & Placebo & $\mathrm{F}$ & 13 & 160 & 2.49 & 1 \\
\hline 5 & Flunisolide & M & 11 & 146 & 2.47 & 6 \\
\hline 6 & Placebo & M & 13 & 157 & 2.50 & 11 \\
\hline 7 & Flunisolide & M & 13 & 162 & 3.03 & 6 \\
\hline 8 & Placebo & M & 10 & 152 & 2.54 & 15 \\
\hline 9 & Flunisolide & M & 7 & 121 & 1.66 & 3 \\
\hline 10 & Flunisolide & $\mathrm{F}$ & 12 & 149 & 2.04 & 3 \\
\hline 11 & Flunisolide & M & 13 & 149 & 2.76 & 12 \\
\hline 12 & Flunisolide & M & 13 & 158 & 3.22 & 2 \\
\hline 13 & Placebo & M & 8 & 125 & 1.87 & 7 \\
\hline 14 & Placebo & M & 10 & 132 & 1.38 & 12 \\
\hline 15 & Flunisolide & M & 10 & 133 & 1.67 & 9 \\
\hline 16 & Flunisolide & M & 9 & 120 & 1.47 & 11 \\
\hline 17 & Placebo & M & 11 & 144 & 2.30 & 9 \\
\hline 18 & Placebo & M & 10 & 139 & 2.01 & 9 \\
\hline 19 & Placebo & M & 9 & 148 & 2.20 & -3 \\
\hline 20 & Flunisolide & M & 11 & 144 & 2.36 & 3 \\
\hline 21 & Placebo & M & 12 & 148 & 2.85 & -12 \\
\hline 22 & Placebo & M & 15 & 148 & 2.54 & 2 \\
\hline 23 & Flunisolide & M & 13 & 150 & 2.14 & 8 \\
\hline 24 & Placebo & M & 12 & 148 & 2.11 & 10 \\
\hline 25 & Flunisolide & M & 7 & 124 & 1.65 & 7 \\
\hline 26 & Flunisolide & $\mathrm{F}$ & 11 & 140 & 1.85 & 8 \\
\hline 27 & Placebo & M & 9 & 134 & 1.90 & 17 \\
\hline 28 & Placebo & $\mathrm{F}$ & 8 & 125 & 1.55 & 10 \\
\hline 29 & Flunisolide & M & 6 & 118 & 1.20 & 3 \\
\hline 30 & Placebo & $\mathrm{F}$ & 11 & 149 & 2.22 & 12 \\
\hline 31 & Placebo & $\mathrm{F}$ & 10 & 140 & 1.63 & 15 \\
\hline 32 & Placebo & M & 8 & 139 & 1.91 & 3 \\
\hline
\end{tabular}

t0: time of admission; FEV1: forced expiratory volume in one second; Rev: reversibility (change in FEV1 after administration of treatment); M: male; F: female.

BARALDi et al. [23] demonstrated that, during the pollen season, FE,NO increased significantly in spite of a lack of significant changes in FEV1, and also showed a relatively high FE,NO in these patients outside the grass pollen season, in agreement with the hypothesis that mild airway inflammation may persist even in the absence of symptoms [14]. A significant time-dependent modulation of FE,NO during house dust mite avoidance has previously been observed in a group of allergic asthmatic children during a stay in the Alpine environment, despite discontinuation of steroid therapy [24].

In the present study, a significant increase in FE,NO was observed in the group of patients treated with placebo, but not in those treated with inhaled flunisolide during 2 weeks of exposure to significant levels of mite allergens. In contrast, no difference has been observed between the two treatments in terms of lung function.

This observation is not unexpected since it is known that airway inflammation may be found in asthmatic patients whose lung function values are normal and clinically well controlled [25]. For this reason, it was recently suggested that the monitoring of lung function and symptoms are not sensitive enough to reflect the extent of airway inflammation [25]. 
The measurement of FE,NO has been proposed as a simple noninvasive means of monitoring the level of airway inflammation $[11-13,16,26]$. It has also been demonstrated that FE,NO is increased after allergen-induced asthmatic reactions [27, 28], whereas it is reduced after treatment with inhaled steroids [15] in a dose-related fashion [14]. The present study design represents a natural antigen-induced challenge and the observed changes in FE,NO in placebo-receiving group suggest that 2 weeks' exposure to significant amounts of mite allergens can be responsible for an increase in airway inflammation in house dust mite-sensitive asthmatic children.

In this study, a period of treatment before leaving the residential house, aimed at reaching a steady-state steroid effect, was not considered since this could have generated significant differences in baseline FE,NO between flunisolide and placebo-treated children. However, previous studies have shown that inhaled steroids significantly reduce FE,NO $[14,15]$, and, therefore, it is tempting to speculate that the lack of changes in FE,NO occurred as a result and not In spite of steroid treatment. Therefore, the authors suggest that treatment with inhaled steroid is able to prevent the increase in FE,NO occurring after a natural allergen challenge.

In conclusion, the expiratory nitric oxide fraction measurement was well accepted by the children who participated in the study, and, from the present results, it is tempting to speculate that expiratory nitric oxide fraction may provide clinical information which would not be revealed by routine lung function testing. Furthermore, by means of this technique, it has been demonstrated that inhaled flunisolide is effective in preventing the increase in airway inflammation in allergic asthmatic children reexposed to allergens, even if, from this study, it is not possible to reach firm conclusions regarding the clinical significance of an increase in expiratory nitric oxide fraction in the absence of measurements of lung function or symptoms.

Acknowledgements. The authors wish to thank M. Fano (Valeas, Milan, Italy) for the statistical analysis and Valeas for providing flunisolide and the nitric oxide analyser.

\section{References}

1. Nathan RA, Kinsman RA, Spector SL, Horton DJ. Relationship between airway response to allergens and non specific bronchial reactivity. J Allergy Clin Immunol 1979; 64: 491

2. Platts-Mills TAE, Tovey ER, Mitchell EB, Moszoro H, Nock P, Wilkins RS. Reduction of bronchial hyperreactivity during prolonged allergen avoidance. Lancet 1982; ii: 675-678.

3. Murray $\mathrm{AB}$, Ferguson AC. Dust free bedroom in the treatment of asthmatic children with house dust mite allergy: a controlled trial. Pediatrics 1983; 71: 418-422.

4. Cockroft DW, Murdock KY. Comparative effects of inhaled salbutamol, sodium cromoglycate, and beclomethasone dipropionate on allergen-induced early asthmatic responses, late asthmatic responses, and increased bron- chial responsiveness to histamine. J Allergy Clin Immunol 1987; 79: 734-740.

5. Dutoit JI, Salome CM, Woolcock AJ. Inhaled corticosteroids reduce the severity of bronchial hyperresponsiveness in asthma but oral theophylline does not. Am Rev Respir Dis 1987; 136: 1174-1178.

6. Jenkins CR, Woolcock AJ. Effect of prednisone and beclomethasone dipropionate on airway responsiveness in asthma: a comparative study. Thorax 1988; 43: 378384.

7. Juniper EF, Kline PA, Vanzieleghem MA. Effect of longterm treatment with an inhaled corticosteroid (budesonide) on airway hyperresponsiveness and clinical asthma in nonsteroid-dependent asthmatics. Am Rev Respir Dis 1990; 142: 832-836.

8. Boner AL, Piacentini GL, Bonizzato C, Dattoli V, Sette L. Effect of inhaled beclomethasone dipropionate on bronchial hyperreactivity in asthmatic children during maximal allergen exposure. Ped Pulmonol 1991; 10: 2-5.

9. Boner AL, Comis A, Schiassi M, Venge P, Piacentini GL. Bronchial reactivity in asthmatic children at high and low altitude: effect of budesonide. Am J Respir Crit Care Med 1995; 151: 1194-1200.

10. Holgate ST. Biomarkers of asthma. Lancet 1998; 351: 1300-1301.

11. Alving K, Weitzberg E, Lundberg JM. Increased amount of nitric oxide in exhaled air of asthmatics. Eur Respir $J$ 1993; 6: 1368-1370.

12. Kharitonov SA, Yates DH, Robins RA, Logan Sinclair R, Shinebourne EA, Barnes PJ. Increased nitric oxide in exhaled air of asthmatic patients. Lancet 1994; 343: 133135.

13. Kharitonov SA, Barnes PJ. Exhaled nitric oxide: a marker of airway inflammation? Curr Opin Anesthesiol 1996; 9: $542-548$.

14. Kharitonov SA, Yates DH, Fan Chung K, Barnes PJ. Changes in the dose of inhaled steroid affect exhaled nitric oxide levels in asthmatic patients. Eur Respir $J$ 1996; 9: 196-201.

15. Kharitonov SA, Yates DH, Barnes PJ. Inhaled glucocorticoids decrease nitric oxide in exhaled air of asthmatic patients. Am J Respir Crit Care Med 1996; 153: 454-457.

16. Lundberg JON, Weitzberg E, Lundberg JM, Alving K. Nitric oxide in exhaled air. Eur Respir J 1996; 9: 26712680.

17. Kharitonov SA, Fan Chung K, Evans D, O'Connor BJ, Barnes PJ. Increased exhaled nitric oxide in asthma is mainly derived from the lower respiratory tract. $\mathrm{Am} J$ Respir Crit Care Med 1996; 153: 1773-1780.

18. Lau-Schadendorf S, Rusche AF, Weber AK, BittnerGoetz P, Whan U. Short term effect of solidified benzyl benzoate on mite allergen concentrations in home dust. $J$ Allergy Clin Immunol 1991; 87: 41-47.

19. Chapman MD, Haymann PW, Wilkins SR, Brown MB, Platts-Mills TAE. Monocipnal immunoassay for the major dust mite (Dermatophagoides) allergens, Der $p \mathrm{I}$ and $\operatorname{Der} f 1$, and quantitative analysis of the allergen content of mite and house dust extracts. J Allergy Clin Immunol 1987; 80: 184-194.

20. Luczynska CM, Arruda LK, Platt-Mills TAE, Miller JD, Lopez M, Chapman MD. A two site monoclonal antibody ELISA for the quantitation of the major Dermatophagoides spp. allergens, Der $p \mathrm{I}$ and Der fl. J Immunol Methods 1989; 118: 227-235.

21. Platts-Mills TAE, Vervloet D, Thomas WR, Aalberse RC, Chapman MD. Indoor allergens and asthma: report of the 
third international workshop. $J$ Allergy Clin Immunol 1997; 100: S1-S23.

22. Grassi M. Statistica in Medicina: un approccio sulla Verosimiglianza. 1st Edn. Milan, McGraw-Hill Libri Italia, 1994; pp. 397-406.

23. Baraldi E, Carra S, Dario C, et al. Effect of natural grass pollen exposure on exhaled NO in asthmatic children. $\mathrm{Am}$ J Respir Crit Care Med 1999; 159: 262-266.

24. Piacentini GL, Bodini A, Costella S, et al. Allergen avoidance is associated with a fall in exhaled NO in asthmatic children. J Allergy Clin Immunol 1999; 104: 1323-1324.

25. Jatakanon A, Lim S, Kharitonov SA, Chung KF, Barnes PJ. Correlation between exhaled nitric oxide, sputum eos- inophils, and methacholine responsiveness in patients with mild asthma. Thorax 1998; 53: 91-95.

26. Kharitonov SA, Alving K, Barnes PJ. Exhaled and nasal nitric oxide measurements: recommendations. Eur Respir $J$ 1997; 10: 1683-1693.

27. Kharitonov SA, O'Connor BJ, Evans D, Barnes PJ. Allergen-induced late asthmatic reactions are associated with elevation of exhaled nitric oxide. Am J Respir Crit Care Med 1995; 151: 1894-1899.

28. Deykin A, Halpeern O, Massaro AF, Drazen JM, Israel E. Expired nitric oxide after bronchoprovocation and repeated spirometry in patients with asthma. Am J Respir Crit Care Med 1998; 157: 769-775. 